\title{
Inhibition of Respiration in Submitochondrial Particles by Uncouplers of Oxidative Phosphorylation ${ }^{1}$
}

\author{
ROBERT E. BEYER AND JANET E. MACDONALD \\ Laboratory of Chemical Biology, Department of Zoology, University of Michigan, \\ Ann Arbor, Michigan 48104 \\ Received August 18, 1969; accepted December 2, 1969
}

\begin{abstract}
High concentrations of uncouplers of oxidative phosphorylation inhibit the oxidation of succinate and NADH catalyzed by phosphorylating beef heart submitochondrial particles. Inhibition is reversed by bovine serum albumin but not by ATP. ATP does not influence either the stimulation of respiration at low uncoupler concentrations or the inhibition of respiration at high uncoupler concentrations. The cytochromes of the electron transfer chain appear to be in the oxidized state during the oxidation of NADH catalyzed by submitochondrial particles partially inhibited by uncoupler, indicating that the inhibitory site resides at, or prior to, the substrate dehydrogenase. These data are consistent with a recent hypothesis which attempts to account for uncoupling action on the basis of competition between uncoupler and substrate molecules for an energy-requiring transport system in the mitochondrial membrane. However, not supportive of such a hypothesis are data indicating that in submitochondrial particles the inhibition does not appear to be of the competitive type and, furthermore, agents and procedures which destroy permeability barriers in mitochondria, and preparations of "open" submitochondrial particles, do not interfere with the uncoupler-mediated inhibition of substrate oxidation by the submitochondrial particle. It is suggested that high uncoupler concentrations interfere with the function of the nonheme iron moieties of the succinic and NADH de hydrogenases. Consistent with this suggestion are the findings that dithiothreitol partially reverses the uncoupler-mediated inhibition of substrate oxidations in submitochondrial particles and also protects against the inhibitory effects of uncoupler. In addition, the nonheme iron components of the succinic and NADH dehydrogenases were reducible by their respective substrates, while the characteristic electron paramagnetic resonance signal of the succinic dehydrogenase nonheme iron moiety was not observed in the uncoupler-inhibited submitochondrial particle upon the addition of NADH.
\end{abstract}

The traditional view of the mechanism of action of uncouplers of oxidative phosphorylation involves the interaction of the uncoupler molecule with a nonphosphorylated, high-energy intermediate of oxidative phosphorylation resulting in the hydrolysis of that high-energy intermediate (2). The po-

1 This investigation was supported by Grant AM 1005603 from the National Institute of Arthritis and Metabolic Diseases of the NIH, and has been the subject of a paper (1) presented before the American Society of Biological Chemists. tential of the intermediate to supply energy to endergonic reactions would thus be dissipated. The finding that concentrations of uncouplers greater than those required for maximal uncoupling inhibit respiration catalyzed by intact mitochondria $(3-5)$ has prompted a reexamination of uncoupler action in several laboratories. Wenncr (6), and Wilson and Merz (7), have presented evidence indicating that high concentrations of uncouplers inhibit the oxidation of substrates in a competitive manner. The demonstration (8) that cytochromes and pyridine nucleo- 
tides were in the oxidized state in mitochondria whose respiration was partially inhibited by uncoupler suggested that substrate was not available to the substrate dehydrogenase.

Direct evidence for the inhibition by uncouplers of substrate entry into mitochondria has been provided by the experiments of Harris, van Dam, and Pressman (9) who reported that high concentrations of uncoupler inhibited the energy-dependent accumulation of substrate. It has been suggested (10) that respiratory inhibition by high uncoupler concentrations is due to inhibition of a substrate transport system located in a mitochondrial membrane. Recently, van Dam and Slater (11) have proposed a general mechanism of uncoupling of respiratory chain phosphorylations involving a cyclic transport of uncoupler which utilizes as the transport vehicle the energyrequiring substrate-transporting system in the inward direction and spontaneous transport in the outward direction. Implicit in the van Dam and Slater hypothesis is a high affinity between the transport system and uncoupler as compared to the affinity between transport system and substrate.

Since submitochondrial particles prepared by sonic vibration are capable of catalyzing efficient oxidative phosphorylation $(12,13)$, as well as other energy-linked functions (14), it was of interest to test the relevance of the van Dam and Slater hypothesis to such submitochondrial systems. This communication reports the inhibition, by a variety of uncouplers of oxidative phosphorylation, of $\mathrm{NADH}$ and succinate oxidation catalyzed by beef heart submitochondrial particles as well as the results of related experiments.

\section{METHODS}

Preparation of ETPH. ${ }^{2} \mathrm{HBHM}$ were prepared from fresh bovine cardiac ventricles essentially as

2 Abbreviations are: ETPH, electron transfer particle from beef heart mitochondria where designations in parentheses refer to key ingredients present during sonic treatment (c.f. Ref. 13); HRHM, heavy layer beef heart mitochondria; Cl-CCP, $m$-Cl-carbonyl cyanide phenylhydrazone; $\mathrm{F}_{3} \mathrm{CCP}, \quad p$-trifluoromethoxy carbonyl cyanide phenylhydrazone; PCSA, 5-C1,3-( $p$-Cl-phenyl), 4'- described by Löw and Vallin (15) except that Tris salts were used, the preparation was not treated with nitrogen gas, homogenization of the tissue was for 30 sec instead of $1 \mathrm{~min}$, and the $\mathrm{pH}$ was maintained at 7.5 except during the separation of light and heavy layers of mitochondria at which time $\mathrm{pH} 7.8$ was employed. Homogenization of the ground tissue was accomplished with a Willem's Polytron, model BEW, rotating at a speed of $14,500 \mathrm{rpm}$ while unloaded. The heavy-layer mitochondrial pellet was washed twice at pH 7.8 in $0.25 \mathrm{~m}$ sucrose- $-0.01 \mathrm{~m}$ Tris $\mathrm{HCl}$ and finally suspended to $30 \mathrm{mg}$ protein per ml. Further details of this mitochondrial preparation have been published recently (16). Submitochondrial particles, ETPH $\left(\mathrm{Mg}^{2+}, \mathrm{Mn}^{2+}\right), \operatorname{ETPH}\left(\mathrm{Mg}^{2+}\right)$, and ETPH(EDTA-1), were prepared as described by Beyer (13). Mitochondria, which had been stored overnight at $-20^{\circ}$, were fragmented with a Branson Sonifier, Model S-75, $20 \mathrm{kc}, 30-45 \mathrm{sec}$, at a power output of between 5 and 6 amp. ETPH (pentane) were prepared by vigorous homogenization in a glass-Teflon homogenizer of $n$-pentane-extracted HBHM prepared according to Szarkowska (17).

Analytical procedures. Protein was estimated by a biuret procedure (18) in which protein was solubilized by the use of approximately $1 \mathrm{mg}$ deoxycholate per $\mathrm{mg}$ of mitochondrial protein. Oxygen consumption was determined with a Clark electrode in 1.5-1.7 ml water-jacketed glass cells (Norman Erway Glass Blowing, Oregon, Wisconsin) maintained at $25^{\circ}$. Signals from the Clark electrode were monitored as described by Estabrook (19) using a Heath EUW-20A servorecorder. Dissolved oxygen was assumed to be $240 \mu \mathrm{M}$ at $25^{\circ}$. All assays of oxygen consumption were determined in a medium (Medium A) consisting of $0.3 \mathrm{M}$ mannitol, $10 \mathrm{~mm} \mathrm{KCl,} 5 \mathrm{~mm} \mathrm{MgCl} 2$, and $5 \mathrm{~mm}$. Tris-phosphate, $\mathrm{pH} 7.5$, in addition to those components indicated in the tables and figures below. Uncouplers were added to assays dissolved in small volumes of ethanol; the resulting ethanol concentration had negligible effect on the rate of substrate oxidation. Differential optical spectra of submitochondrial particles were ob-

Cl-salicylanilide; BNSA, 5-Cl,3-t-butyl, $2^{\prime}$ - $\mathrm{Cl}, 4^{\prime}$ $\mathrm{NO}_{2}$-salicylanilide; BSA, bovine serum albumin; DNP, 2,4-dinitrophenol; SDS, sodium dodecyl sulfate, DOC, deoxycholate; DTT, dithiothreitol; EPR, electron paramagnetic resonance; $\mathrm{FeNH}_{\mathrm{N}}$, nonheme iron protein associated with $\mathrm{NADH}$ dehydrogenase (EC 1.6.99.3); $\mathrm{FeNH}_{\mathrm{S}}$, nonheme iron protein associated with succinate dehydrogenase ( $\mathrm{EC}$ 1.3.99.1); $\mathrm{FeNH}_{\mathrm{R}}$, nonheme iron protein associated with the cytochrome $b$-cytochrome $c_{1}$ segment of the electron transfer chain. 
tained with an Aminco-Chance dual-wavelength/ split-beam spectrophotometer operating in the split-beam mode.

$\mathrm{X}$-band $(9 \mathrm{GHz})$ EPR spectra were obtained with a Varian V-4500 spectrometer equipped with a microwave bridge and a circulator (20). A lowtemperature accessory resembling that described by Hansen, Kalal, and Beinert (21) without the automatic temperature control was employed. Samples $(0.25-\mathrm{ml})$ of normal or uncoupler-inhibited ETPH(EDTA-1) (approximately $100 \mathrm{mg}$ protein per $\mathrm{ml}$ ) were placed into $3 \mathrm{~mm}$ (id) quartz EPR tubes. Other reagents were layered on the ETPH(EDTA-1) with the use of long micropipets. Efficient stirring was accomplished with a handagitated nichrome wire which terminated in a small loop. Samples were subsequently centrifuged for approximately $10 \mathrm{sec}$ in a bench-top centrifuge to remove included air, incubated for the requisite amount of time, and then frozen in liquid nitrogen. The operations of stirring, centrifuging, incubation, and freezing were standardized to facilitate comparison of samples.

Materials. All reagents were of analytical reagent grade or equivalent whenever possible and were used without further purification. Filtered, deionized, glass-distilled water was used for all solutions. Cl-CCP and $\mathrm{F}_{3} \mathrm{CCP}$ were gifts from Dr. Peter Heytler, and the salicylanilides, PCSA and BNSA, were supplied by Philip C. Hamm of Monsanto Co., St. Louis, Mo. Tyrocidin and gramicidin were purchased from Mann Research Laboratories and NADH from P-L Biochemicals. Crystalline BSA was obtained from Armour Pharmaceutical Co. The detergents Teepol 610 and Nonidet P-40 were gif ts of the Shell Chemical Co. Triton X-100 and X-114 were generously supplied by Rohm and Hass. Subtilopeptidase A (Nagarse) was purchased from Enzyme Development Corp., New York, and phospholipase A (Crotalus atrox venum) was purchased from Ross Allen's Reptile Institute, Silver Springs, Florida, and treated aceording to Allmann et al. (22) prior to use. Preparation B from rat liver mitochondria treated with digitonin was generously supplied by $\mathrm{Dr}$. Cecil Cooper.

\section{RESULTS}

The effects of a number of uncouplers of oxidative phosphorylation on the oxidation of NADH catalyzed by ETPH $\left(\mathrm{Mg}^{2+}, \mathrm{Mn}^{2+}\right)$ are shown in Fig. 1. All of the compounds tested and shown in Fig. 1 induced a biphasic response of NADH oxidation, i.e., a stimulation of the rate of oxidation followed by progressive inhibition at higher uncoupler concentrations. The concentration at which the uncouplers stimulated the oxidation of $\mathrm{NADH}$ was roughly proportional to their efficacy in uncoupling the phosphorylation of ADP from electron transfer. RNSA, which has been reported (23) to give half maximal uncoupling at approximately $10^{-8} \mathrm{M}$, resulted in maximal respiratory stimulation in the submitochondrial particle at $10^{-6} \mathrm{M}$, while tyrocidin, which increases the permeability of intact mitochondria to sodium ions (24) and also may act as an uncoupler of oxidative phosphorylation in the absence of exogenous sodium or potassium in $\operatorname{ETPH}\left(\mathrm{Mg}^{2+}, \mathrm{Mn}^{2+}\right)$ (25), was the least effective respiratory stimulator. It should be noted that the experiments from which the data in Fig. 1 were

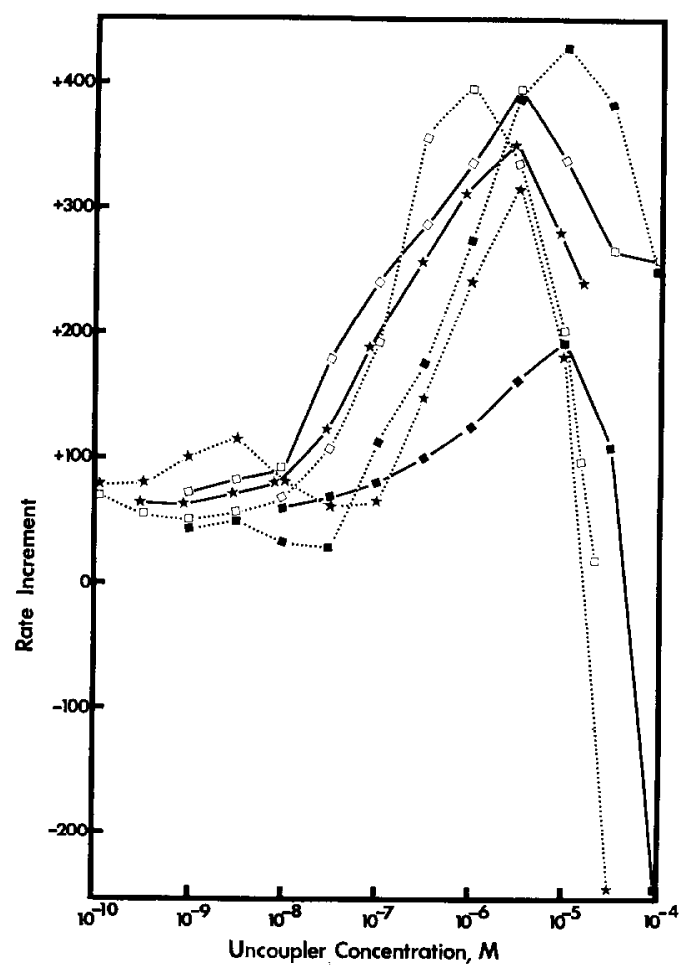

Fig. 1. The effect of uncouplers on NADH soxidation catalyzed by $\mathrm{ETPH}\left(\mathrm{Mg}^{2+}, \mathrm{Mn}^{2+}\right)$. As ays were performed as described in the Methodssection. Enzyme protein $(0.45 \mathrm{mg})$ was used in each case. Rate Increment refers to the rate of NADH oxidation in the presence of uncoupler minus the rate of $\mathrm{NADH}$ oxidation in the absence of uncoupler in natoms oxygen $/ \mathrm{min} / \mathrm{mg}$ enzyme protein. Symbols used: $\mathbf{\square}-\mathbf{0}$, tyrocidin; $\mathbf{\square}-\mathbf{\square}, \mathrm{Cl}-\mathrm{CCP} ; \square-\square$, gramicidin; $₫ \longrightarrow \star$, $\mathrm{F}_{3} \mathrm{CCP} ; \square--\square, \mathrm{BNSA} ; \star--\star$, PCSA. 


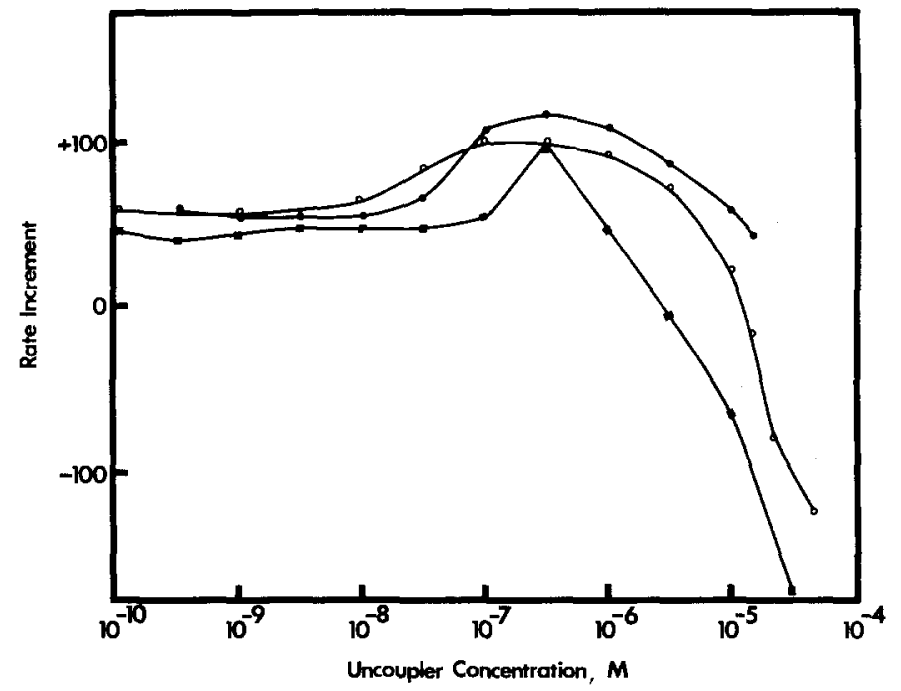

Frg. 2. The effect of uncouplers on succinate oxidation catalyzed by ETPH $\left(\mathrm{Mg}^{2+}\right.$, $\mathrm{Mn}^{2+}$ ). Assays were performed as deseribed in the Methods section. Rate increment and

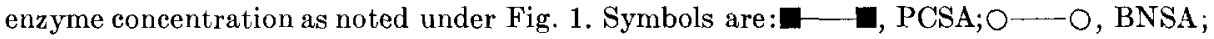
$-\mathrm{F}_{3} \mathrm{CCP}$.

derived were performed in the absence of exogenous ADP as phosphate acceptor, although the submitochondrial particles employed contain approximately 2.7 nmoles of adenine nucleotide per $\mathrm{mg}$ of particle protein (26). At high concentrations all of the uncouplers shown in Fig. 1 inhibited NADH oxidation catalyzed by $\mathrm{ETPH}\left(\mathrm{Mg}^{2+}, \mathrm{Mn}^{2+}\right)$. Tyrocidin, PCSA, and BNSA were especially potent in this respect and resulted in inhibitions to bclow the original (i.c., no uncoupler present) levels of oxidation.

Qualitatively similar results were obtained using succinate as substrate (Fig. 2) although fewer uncouplers were tested in this respect. With succinate as substrate, and employing $\operatorname{ETPH}\left(\mathrm{Mg}^{2+}, \mathrm{Mn}^{2+}\right)$ as enzyme as in the experiments shown in Fig. 1, the extremes of stimulation and inhibition were quantitatively smaller than with $\mathrm{NADH}$ as substrate. It should be noted, however, that the ratio of the rate of succinate oxidation to the rate of $\mathrm{NADH}$ oxidation catalyzed by this type of submitochondrial particle is lower than the same ratio for the intact mitochondrial system (in state 3 ), indicating a rate limitation between the dehydrogenation of succinate and the reduction of coenzyme $Q$ incurred during the preparation of ETPH (c.f. 27). We have also attcmpted to obtain inhibition of respiration by PCSA using ascorbate and $N, N, N^{\prime}, N^{\prime}$-tetramethyl-p-phenylenediamine as substrate without success.

Experiments similar to those reported in Figs. 1 and 2 have been performed using DNP as uncoupler (data not shown). Although this uncoupler may inhibit respiration of intact mitochondria, such was not the case with the three types of submitochondrial particles used in this study. No inhibitory phase was observed after the initial respiratory stimulation. Owing to concentration limitations the highest concentration of DNP used was 1.8 mu. In general, however, the submitochondrial particles appear to be more resistant to the inhibitory effects of uncouplers than are intact mitochondria.

Since Papa et al. (28) have reported that ATP and BSA reverse the inhibition of succinate oxidation by dicoumarol catalyzed by rabbil-kidney mitochondria, it was of interest to investigate these effects in the submitochondrial particle. ATP did not relieve the inhibition which PCSA imposed upon the oxidation of NADH catalyzed by $\operatorname{ETPH}\left(\mathrm{Mg}^{2+}, \mathrm{Mn}^{2+}\right)$ at either low $(0.59 \mathrm{~mm})$ or high (8.8 mu) ATP concentrations (Table I). On the other hand, the addition of BSA to the inhibited system partially reversed 
TABLE I

EFFeCts of ATP AND BSA on NADH and Succinate Oxidation INHIBITED BY UNCOUPLER ${ }^{a}$

\begin{tabular}{lllc}
\hline Expt. & Substrate & Additions ( $\mu$ moles) & $\begin{array}{c}\text { Rate } \\
\text { (natoms/ } \\
\text { min/mg } \\
\text { protein) }\end{array}$ \\
\hline 1 & NADH & None & 761 \\
& & PCSA (0.17) & 141 \\
& & ATP (1) & 109 \\
2 & NADH & ATP (15) & 109 \\
& & None & 907 \\
3 & Suceinate & PCSA (0.17) & 122 \\
& & BSA (0.25 mg) & 526 \\
& & None & 377 \\
4 & Succinate (0.17) & 54 \\
& & BSA (0.25 mg) & 181 \\
& & BSA (0.25 mg) & 247 \\
& & None & 321 \\
& & PCSA (0.17) & 36 \\
& & Succinate (8) & 36 \\
& & Succinate (20) & 36 \\
& & Succinate (40) & 38 \\
\hline
\end{tabular}

a The reaction cuvette contained, in a total volume of $1.70 \mathrm{ml}$ of Medium A; $0.45 \mathrm{mg}$ ETPH$\left(\mathrm{Mg}^{2+}, \mathrm{Mn}^{2+}\right)$ protein; $2.5 \mu$ moles $\mathrm{NADH}$ or 20 $\mu$ moles succinate to initiate the reaction except in Expt. 4 in which the reaction was initiated by the addition of $2 \mu$ moles succinate. Additions were in the order given in the Table.

the inhibition of both succinate and NADH oxidation. The effect of BSA would appear to be a true reversal of inhibition and not merely a stimulation of noninhibited electron transfer chains since the addition of comparable quantities of $\mathrm{BSA}$ to $\mathrm{ETPH}\left(\mathrm{Mg}^{2+}\right.$, $\mathrm{Mn}^{2+}$ ) oxidizing these substrates results in variable stimulations of oxidation, but never exceeding $10 \%$ of the control rate.

To test the possible competitive nature of the inhibition of respiration by uncouplers in the submitochondrial particle an experiment was performed in which the reaction was initiated by a low concentration of succinate $(1.18 \mathrm{~mm})$, oxidation inhibited by PCSA, and the effect of additional succinate $(5.88 \mathrm{~mm}, 17.64 \mathrm{~mm}$, and $41.18 \mathrm{~mm}$ ) noted. No reversal of inhibition was observed (Table I, Expt. 4).

Van Dam (8) has reported that in the presence of ADP low concentrations of uncoupler inhibited respiration of intact mito- chondria. That such was not the case in submitochondrial particles is indicated by the data presented in Fig. 3 where the effect of increasing concentrations of the uncoupler, PCSA, in the presence and absence of $1 \mathrm{~mm}$ ADP, on the oxidation of NADH is shown. Over a wide range of PCSA concentrations (between $10^{-4}$ and $10^{-10} \mathrm{M}$ ) the presence of ADP was without significant effect, although the biphasic response to the uncoupler noted above was observed.

In order to localize the point of inhibition by uncouplers in the submitochondrial particle, differential optical spectra were obtaincd during the oxidation of NADH eatalyzed by partially inhibited and control $\operatorname{ETPH}\left(\mathrm{Mg}^{2+}\right)$ (Fig. 4). Since the electrontransfer components of sonic submitochondrial particles are almost completely in the oxidized state during steady-state electron transfer with NADH as substrate, KCN was added at a concentration (0.01 $\mathrm{mm})$ which partially inhibited electron transfer so that overall rate of $\mathrm{NADH}$ catalyzed by the control particle was still greater than the

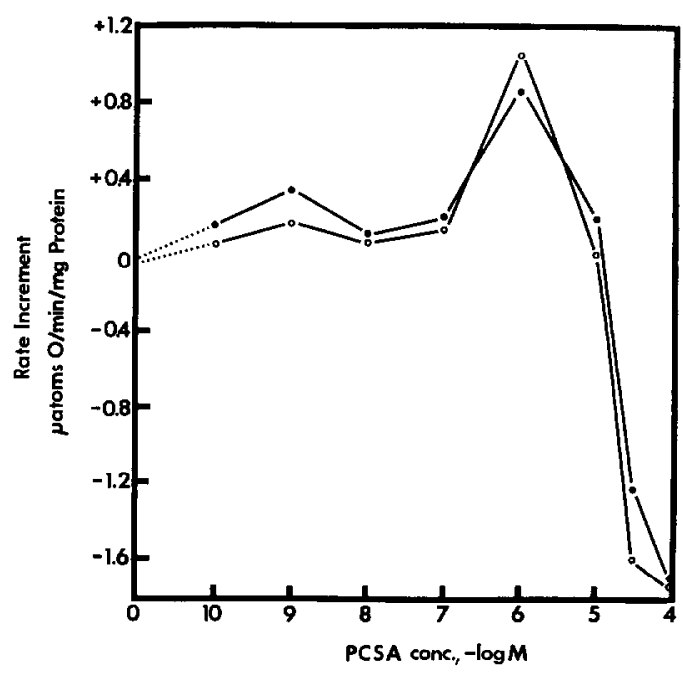

FIG. 3. Effect of ADP on the inhibition by uncoupler of NADH oxidation by ETPH (EDTA1). Conditions of assay were as described in Methods and under Fig. 1 except that Rate Increment is in units of $\mu$ atoms oxygen $/ \mathrm{min} / \mathrm{mg}$ enzyme protein. The ADP concentration was 1 mu. Symbols are: $O-O$, ADP present; - - no ADP. Dotted lines are extrapolations to zero uncoupler concentration. 


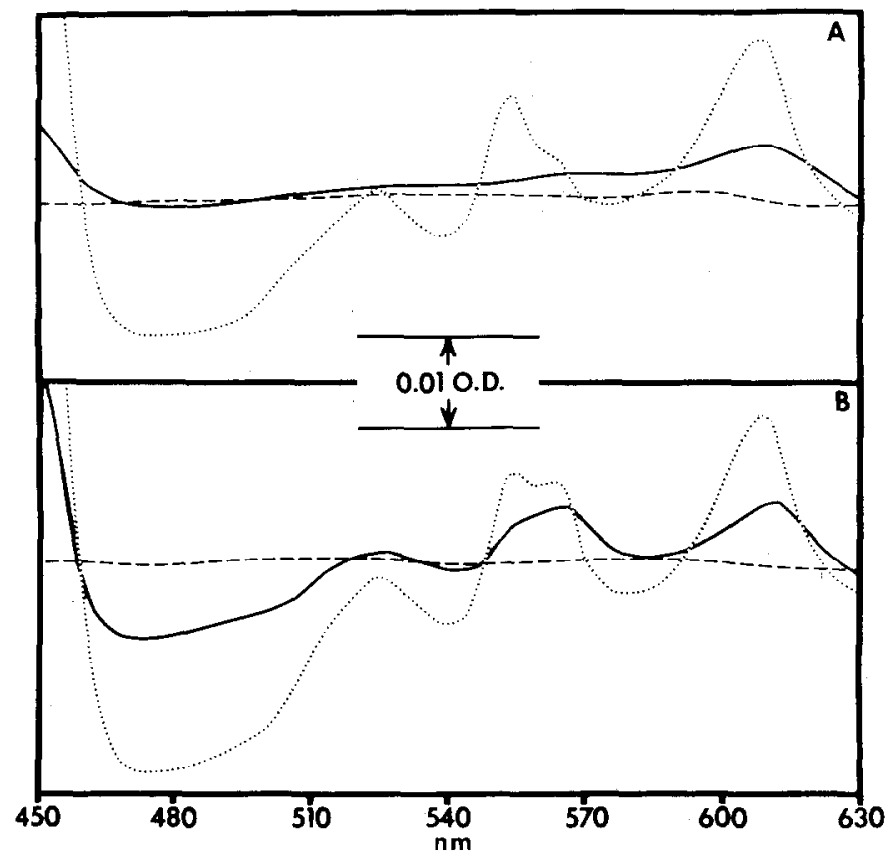

FIg. 4. Differential optical spectra of control and PCSA-inhibited ETPH( $\left.\mathrm{Mg}^{2+}\right)$. To 4 $\mathrm{ml}$ of $\mathrm{ETPH}\left(\mathrm{Mg}^{2+}\right)$ at a protein concentration of $30 \mathrm{mg} / \mathrm{ml}$ was added $33 \mathrm{~mm}$ PCSA until the rate of NADH oxidation had fallen from 680 natoms oxygen $/ \mathrm{min} / \mathrm{mg}$ protein (control rate) to 256 natoms oxygen $/ \mathrm{min} / \mathrm{mg}$ protein. The amount of PCSA required was 0.1 $\mu \mathrm{mole} / \mathrm{mg}$ protein. The control suspension was treated identically except that an equivalent volume of ethanol was added. The suspensions were centrifuged at $151,000 \mathrm{~g}_{\mathrm{avg}}$ for 20 min and suspended in $0.25 \mathrm{~m}$ sucrose to a concentration of $30 \mathrm{mg}$ protein $/ \mathrm{ml}$. Two tenths milliliter of each preparation was diluted to $6 \mathrm{ml}$ with Medium A and KCN was added to a concentration of $0.01 \mathrm{~mm}$. This amount of $\mathrm{KCN}$ lowered the rate of $\mathrm{NADH}$ oxidation in the control preparation to 445 natoms oxygen $/ \mathrm{min} / \mathrm{mg}$ protein. Spectra were obtained by adding $2.5 \mathrm{ml}$ of the ETPH $\left(\mathrm{Mg}^{2+}\right)$ preparations to each of two cuvettes $(10-\mathrm{mm}$ path $)$ and scanning between 450 and $630 \mathrm{~nm}$ using an Aminco-Chance dual-wavelength/split-beam spectrophotometer in the split-beam mode with the cuvette compartment maintained at $25^{\circ}$. Recording speed was $5 \mathrm{~nm} / \mathrm{sec}$ and the recorder was set at 0.1 OD full scale. Twenty microliters of water were added to the reference cuvette, and the same volume of $0.1 \mathrm{M}$ NADH was added to the sample cuvette. The spectrum was obtained immediately so as to record the steady-state levels of cytochrome oxido-reduction. (-). Upon full anaerobiosis the spectrum was recorded again $(---)$. The base lines appear as $(--)$. Spectra of PCSA-inhibited particles appear in part A; control particle spectra appear in part B.

particle inhibited by PCSA. The rates of NADH oxidation catalyzed by the submitochondrial particles used in the experiment shown in Fig. 4 were: Control $+\mathrm{KCN}, 445$ natoms oxygen $/ \mathrm{min} / \mathrm{mg}$ protein; PCSA-inhibited + KCN, 256 natoms oxygen/ $\mathrm{min} / \mathrm{mg}$ protein. The rate of $\mathrm{NADH}$ oxidation catalyzed by the PCSA-inhibited particle preparation was not altered by the addition of $0.01 \mathrm{~mm} \mathrm{KCN}$, indicating that the site of PCSA inhibition was on the substrate side of the cytochrome oxidase. The steady-state oxido-reduction levels of the PCSA-inhibited particles (solid line, part A, Fig. 4) indicated that flavins (465 $\mathrm{nm})$, cytochromes $c+c_{1}(552 \mathrm{~nm})$, cytochrome $b$ $(562 \mathrm{~nm})$, and cytochromes $a+a_{3}(605 \mathrm{~nm})$ were all more oxidized than these same electron-transfer components in the control particle (solid line, part B,Fig. 4). These observations would indicate that the site inhibited by PCSA was at least prior to interaction of electrons with cytochrome $b$. The reduced spectra (dotted lines) are included to indicate 
TABLE II

Additive Effect of Uncouplers on Inhibition OF NADH OXIDATION BY ETPH(EDTA-1) ${ }^{a}$

\begin{tabular}{llc}
\hline Expt. & \multicolumn{1}{c}{ Addition } & $\begin{array}{c}\text { Increment } \\
\text { (natoms } \\
\text { oxgen } / \text { min/ } \\
\text { mg protein) }\end{array}$ \\
\hline 1 & Tyrocidin $\left(5 \times 10^{-5} \mathrm{M}\right)$ & -348 \\
2 & PCSA $\left(2 \times 10^{-5} \mathrm{M}\right)$ & -348 \\
& Tyrocidin $\left(5 \times 10^{-5} \mathrm{M}\right)$ & -514 \\
\hline
\end{tabular}

${ }^{a}$ Rates of oxidation were assayed polarographically in $1.7 \mathrm{ml}$ of Medium A. In addition the system contained $0.3 \mathrm{mg}$ of submitochondrial particle protein, and $2.5 \mu$ moles NADH were added to initiate the reaction. Uncouplers were added in small volumes of ethanol which had insignificant effects on the rate of oxidation. Final concentrations of uncouplers are given in parentheses. Increment refers to (NADH oxidation rate in presence of uncoupler)-(initial NADH oxidation rate). The initial rate in the absence of uncoupler was 892 natoms oxygen $/ \mathrm{min} / \mathrm{mg}$ enzyme protein. In Expt. 2 tyrocidin was added after PCSA.

TABLE III

Ehfect of Membrane "Solubilizing" Procedures on Inhibition of NADH OXIDATION ${ }^{a}$

\begin{tabular}{lcc}
\hline \multicolumn{1}{c}{ Reagent added } & \multicolumn{1}{c}{ Concentration } & Rate \\
\hline Control & - & 822 \\
PCSA-inhib. con- & - & 456 \\
$\quad$ trol & & \\
Teepol 610 & $33-66 \mu \mathrm{g} / \mathrm{mg}$ protein & 467 \\
Sodium oleate & $75 \mu \mathrm{moles} / \mathrm{mg}$ protein & 441 \\
Nonidet P-40 & $1.3 \mu \mathrm{g} / \mathrm{mg}$ protein & 439 \\
SDS & $7 \mu \mathrm{g} / \mathrm{mg}$ protein & 461 \\
Tween 80 & $1.3 \mu \mathrm{g} / \mathrm{mg}$ protein & 455 \\
DOC & $3.3 \mathrm{mg} / \mathrm{mg}$ protein & 441 \\
Triton X-114 & $3.3 \mu \mathrm{g} / \mathrm{mg}$ protein & 456 \\
Triton X-100 & $7 \mu \mathrm{g} / \mathrm{mg}$ protein & 461 \\
\hline
\end{tabular}

\begin{tabular}{lcc}
\hline \multirow{2}{*}{ Pretreatment } & \multicolumn{2}{c}{ Rate } \\
\cline { 2 - 3 } & - PCSA & + PCSA \\
\hline Subtilopeptidase A & 489 & 259 \\
Phospholipase A & 522 & 264 \\
"Solubilized," Tzagoloff et & 922 & 378 \\
$\quad \begin{array}{l}\text { al. (29) } \\
\text { Triton X-100 }\end{array}$ & 870 & 468 \\
Digitonin prep. B, Hoppel & 627 & 291 \\
$\quad$ and Copper (30) & & \\
ETPH (pentane) & 503 & 241 \\
\hline
\end{tabular}

${ }^{a}$ Tests of the ability of agents to release the inhibition of $\mathrm{NADH}$ oxidation were performed in that upon anaerobiosis the electron transfer components were capable of observable spectral changes, although cytochrome $b$ of the PCSA-inhibited particle did not appear to be capable of full reduction.

Concentrations of both tyrocidin and PCSA which were slightly inhibitory were added to ETPH(EDTA-1) during the oxidation of NADH in order to ascertain if the inhibitory effects of uncouplers were additive (Table II). From the data presented in Table II it would be expected that the combination of the two uncouplers would result in an inhibition of respiration from the initial rate in the absence of uncouplers of -696 natoms of oxygen $/ \mathrm{min} / \mathrm{mg}$ protein. Addition of the two uncouplers resulted in an increment of -514 natoms of oxygen $/ \mathrm{min} / \mathrm{mg}$ protein, indicating that the inhibitory effects of the uncouplers were partially additive.

cuvettes containing $1.5 \mathrm{ml}$ Medium A, 0.3 or 0.45 mg ETPH protein, and the reaction was initiated by the addition of $2.5 \mu$ moles NADH. The initial rate of oxidation was recorded and 33 nmoles of PCSA were added to partially inhibit respiration. Compounds were subsequently added to assay their capacity to overcome the uncoupler-imposed inhibition. These data appear in the upper portion of the table. Pretreatment experiments consisted of various treatments of the ETPH prior to incubation in the oxygen electrode cuvette, and were as follows: Triton $\mathrm{X}-100$ was added to ETPH(EDTA-1) at a protein concentration of $30 \mathrm{mg} / \mathrm{ml}$ to either 0.1 or $0.2 \%$ and incubated at $40^{\circ}$ for 30 min; $2 \mathrm{mg}$ of subtilopeptidase A (Nagarse) were added to $3 \mathrm{ml}$ of ETPH(EDTA-1) at a concentration of $10 \mathrm{mg}$ protein $/ \mathrm{ml}$ and incubated at room temperature with constant stirring. $\mathrm{pH}$ was maintained at 7.5 with the glass electrode. Portions were removed after $6,15,30$, and $60 \mathrm{~min}$ for assay of NADH oxidase activity and extent of inhibition by PCSA; $5 \mathrm{mg}$ of crude phospholipase A (lyophilized venom of Crotalus atrox) treated according to Allmann et al. (22) was incubated exactly as described above for subtilopeptidase A; "solubilized" repeating units were prepared from alkaline ETP as described by Tzagoloff, McConnell, and MacLennan (29); submitochondrial particles from rat liver mitochondria prepared with digitonin were Preparation B of Hoppel and Cooper (30). All detergents tested in the experiment shown in the upper portion of the table caused inhibition at concentrations higher than those listed in the table. All rates are in terms of natoms $/ \mathrm{min} / \mathrm{mg}$ protein. 
An implication of the van Dam and Slater hypothesis is that disruption of a membrane which constitutes a barrier between substrate and its dehydrogenase, in this case the "overutilization" of the substrate transport system by uncoupler, ought to result in the loss of the ability of uncoupler to inhibit substrate oxidation. This implication has been examined by two types of experiments, the data from which are presented in Table III. In the first series of experiments agents which might be expected to render the submitochondrial membrane either soluble or disrupted were tested as to their ability to release the inhibition of $\mathrm{N} \Lambda \mathrm{DH}$ oxidation imposed by the uncoupler PCSA. Of the eight ionic and nonionic detergents employed, none was successful in releasing inhibition (Table III). The concentrations of detergents used were slightly lower than those resulting in inhibition of $\mathrm{NADH}$ oxidation in ETPH not treated with uncoupler. The second type of experiment shown in Table III was designed to test the ability of uncouplers to inhibit enzyme preparations treated, prior to incubation, in such a way as to render them "open" or "soluble." Digestion of ETPH(EDTA-1) with either the protease subtilopeptidase $A$ or phospholipase A did not produce a particle resistant to the inhibitory effects of uncoupler. The use of a "soluble" repeating unit preparation described by Tzagoloff, McConnell, and MacLemman (29) and the "open," partially lamellar submitochondrial preparation of Hoppel and Cooper (30) were both inhibited by high uncoupler concentrations, as was a submitochondrial particle derived from the $n$-pentane-extracted HBHM preparation of Szarkowska (17).

The possibility that uncouplers were complexing with - SH groups in the electron transfer chain prior to the cytochromes was examined by testing the ability of dithiothreitol to protect from or release the inhibitory effects of the uncoupler PCSA. The addition of dithiothreitol to particles inhibited by uncoupler resulted in partial restoration of the initial rate of NADH oxidation (Table IV, Expt. 1). That this stimulation was not merely the result of a stimulatory effect on electron transfer units not affected by uncoupler was indicated by the somewhat greater percentage stimulation of the inhibited than the uninhibited particle (Table IV, Expt. 2). The - SH group protector was also effective in providing some degree of protection against the effect of PCSA (Table IV, Expt. 2 and 3). Two other -SH group protectors, 2-mercaptoethanol and 2,3-dimercaptopropanol, were studied in the same manner, but afforded little or no protection or restoration (data not shown).

If the rate limitation of an uncouplerinhibited electron transfer chain were due to a lack of substrate transport it would be cxpected that the nonheme iron components of the NADH and succinate dehydrogenases would remain in the oxidized states upon the addition of substrate. Such was not the case when the nonheme iron components of the submitochondrial particle were observed with the EPR spectrometer (Fig. 5). Both the control and the uncoupler-inhibited ETPH(EDTA 1) in the oxidized state showed the characteristic EPR signal for copper of the cytochrome oxidase (EC 1.9.3.1) at $g=2.00$ (31) and lack of iron signals. The addition of NADH to the control particle resulted in the appearance of the characteristic signals at $g=1.94$ for $\mathrm{FeNH}_{\mathrm{N}}, \mathrm{FeNH}_{\mathrm{S}}$ (31), at $g=1.90$ for

\section{TABLE IV}

\begin{tabular}{|c|c|c|c|}
\hline Expt. & Additions & $\begin{array}{c}\text { Rate } \\
\text { (natoms oxygen/' } \\
\text { min/mg protein) }\end{array}$ & $\begin{array}{c}\% \\
\text { Change }\end{array}$ \\
\hline \multirow[t]{3}{*}{1} & NADH & 826 & - \\
\hline & PCSA & 307 & -63 \\
\hline & DTT & 448 & +46 \\
\hline \multirow[t]{3}{*}{2} & $\mathrm{NADH}$ & 778 & - \\
\hline & DTT & 1040 & +34 \\
\hline & PCSA & 596 & -43 \\
\hline \multirow[t]{2}{*}{3} & DTT, NADH & 867 & 一 \\
\hline & PCSA & 512 & -41 \\
\hline
\end{tabular}

a Rates of oxidation were assayed with the Clark electrode in $1.5 \mathrm{ml}$ of Medium $\mathrm{A}$. In addition the system contained $0.45 \mathrm{mg}$ of ETPH(EDTA-1) protein and $2.5 \mu$ moles of NADH were added to initiate the reaction. When present, DTT was $0.83 \mathrm{mM}$ and PCSA was $0.11 \mathrm{~mm}$. The order of additions was as given in the Table. 


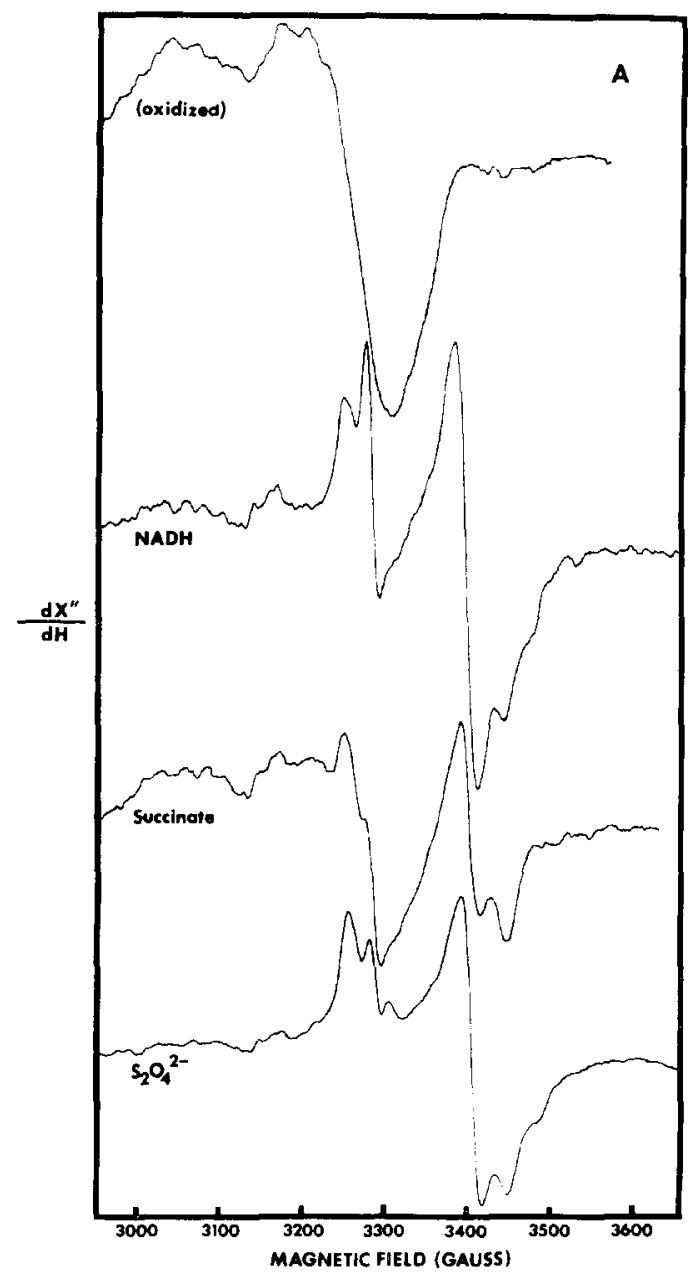

Fig. 5. The effect of a high concentration of PCSA on the EPR spectra of ETPH(EDTA-1). A, normal ETPH(EDTA-1) which were treated identically to the inhibited enzyme except that ethanol, which was added during the incubation to cause inhibition, did not contain uncoupler. B, uncoupler-inhibited ETPH(EDTA-1) treated as follows: $7 \mathrm{ml}$ of ETPH(EDTA-1) containing 30 $\mathrm{mg}$ of protein per $\mathrm{ml}$ were incubated at $30^{\circ}$ for 180 min during which time $1 \mathrm{ml}$ in $50-\mu l$ portions of $33 \mathrm{~mm}$ PCSA in ethanol was added. After each addition of PCSA the rate at which NADH was oxidized was assayed. At the end of the incubation period the rate of NADH oxidation catalyzed by the uncoupler-treated enzyme was 43 natoms oxygen $/ \mathrm{min} / \mathrm{mg}$ protein while the ethanol-treated enzyme (A) catalyzed NADH oxidation at a rate of 250 natoms oxygen $/ \mathrm{min} / \mathrm{mg}$ protein. The particles were centrifuged $(155,000 \mathrm{~g}, 30 \mathrm{~min})$ and were washed twice in $0.25 \mathrm{~m}$ sucrose containing $0.01 \mathrm{M}$ Tris $-\mathrm{HCl}, \mathrm{pH}$ 7.5. The final sediments

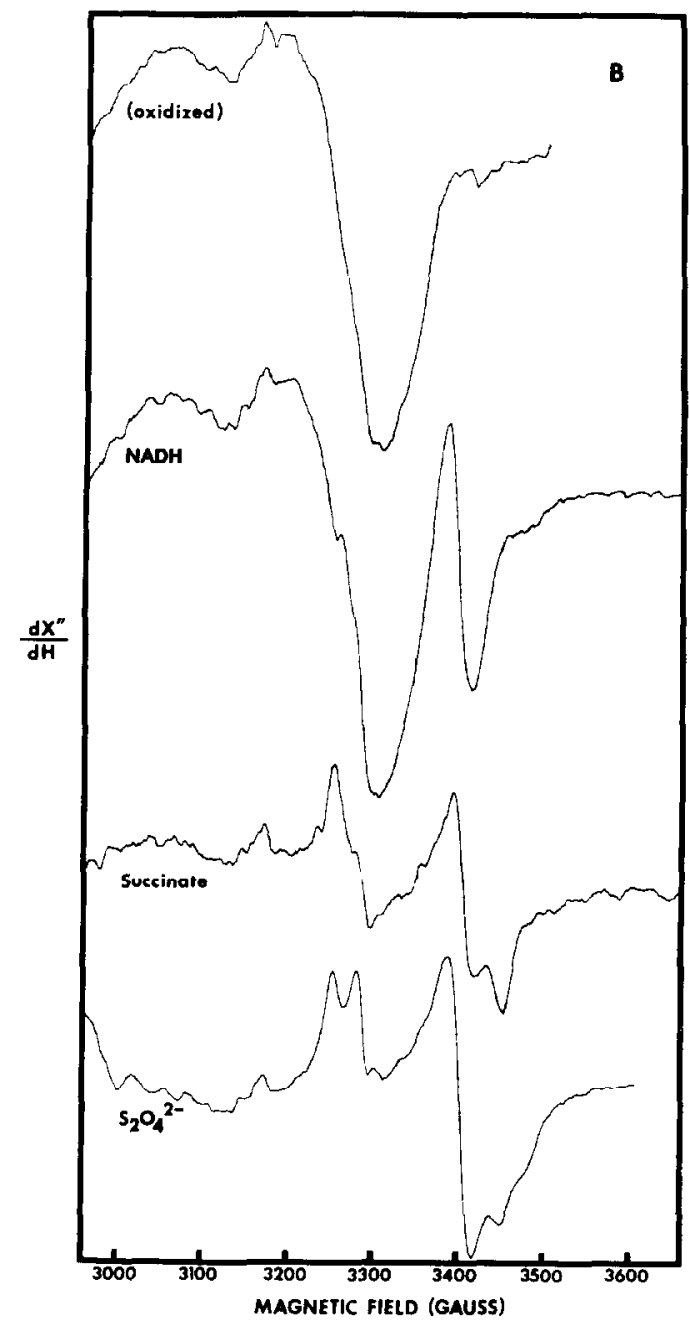

were employed for EPR spectra. The uppermost traces in A and B, labeled oxidized, refer to enzyme to which no substrate was added. The spectra labeled NADH and succinate had $5 \mu \mathrm{l}$ of $1 \mathrm{M}$ substrate added and were treated as described in the Methods section. A few grains of $\mathrm{Na}_{2} \mathrm{~S}_{2} \mathrm{O}_{4}$ produced the lowermost, reduced spectra. Spectra were recorded at $88^{\circ} \mathrm{K}$ with the following instrumental conditions: modulation amplitude, $12 \mathrm{G}$; microwave power, $19 \mathrm{~mW}$; magnetic field sweep, $200 \mathrm{G} / \mathrm{min}$; time constant, 1 sec.

$\mathrm{FeNH}_{\mathfrak{R}}$ (32), and the disappearance of the copper signal at $g=2.00$, indicating full communication of electrons from $\mathrm{NADH}$ with all segments of the submitochondrial electron transfer chain (Fig. 5, part A, $\mathrm{NADH}$ ). The addition of NADH to the uncoupler-inhibited particle, however, elicited 
only the $\mathrm{FeNH}_{\mathrm{N}}$ signal at $g=1.94$ and did not result in a loss of the copper signal at $g=2.00$, indicating a lack of communication of electrons from NADH with the cytochrome and succinate dehydrogenase portions of the electron transfer chain (Fig. 5, part $\mathrm{B}, \mathrm{N} \Lambda \mathrm{DH})$. The appcarance of the $g=1.94$ signal characteristic of $\mathrm{FeNH}_{\mathrm{S}}$ upon the addition of succinate suggested that the $\mathrm{FeNH}_{\mathrm{s}}$ was fully functional in the uncouplerinhibited particle (Fig. 5, part B, succinate). The loss of the copper signal at $g=2.00$ under this condition indicates that the block was not complete in the succinate oxidase chain. The same addition is shown with the control preparation for purposes of comparison (Fig. 5, part A, succinate). The fully reduced enzyme preparations are shown in the bottom trace of each part of Fig. 5, $\mathrm{S}_{2} \mathrm{O}_{4}{ }^{2-}$.

\section{DISCUSSION}

There appears to be general agreement on the view that the permeability of mitochondria to substrates is restricted and that special energy-utilizing mechanisms are required in the rapid entry of many substrates so as to be accessible to their respective dehydrogenases $(33,34)$. The same type of phenomenon has been shown to apply to the incorporation of NAD (35) and other types of compounds into mitochondria. No such permeability barriers have been demonstrated for submitochondrial particles produced by sonic vibration, i.e., ETPH, although data indicating that a permeability barrier to sodium and potassium ions exists in such particles have been presented (25). Several lines of evidence presented in this communication are consistent with the hypothesis of van Dam and Slater (11) which explains the action of uncouplers of oxidative phosphorylation on the basis of a competition between substrate and uncoupler for the energy utilizing substrate transport system of the mitochondrion. For example, high concentrations of uncoupler severely inhibit the respiration of $\mathrm{NADH}$ and succinate catalyzed by beef heart submitochondrial particles. Such particles are capable of varying degrees of phosphorylative efficiency (12, 13) but are far from devoid of such activity. Van Dam (8) has reported such inhibition for nonphosphorylating submitochondrial particles. In this connection it is of interest to note that in addition to traditional uncoupling agents, tyrocidin, which induces ion transport in intact mitochondria (24), also exhibits an inhibitory action on ETPH. Also consistent with the van Dam and Slater hypothesis is the observation that the electron transfer chain components of ETPH are essentially completely oxidized in the uncoupler-induced partially inhibited respiratory state, indicating that the point of inhibition is at a site prior to the succinate or NADH dehydrogenase levels and possibly at the site of substrate transport across the submitochondrial membrane. These observations are also consistent with those of Quagliariello and Palmieri $(36,37)$ and others on the loss of substrate from mitochondria in the presence of uncoupler.

However, certain observations presented herein are at variance both with those obtained with intact mitochondria and with the van Dam and Slater hypothesis (11). First, it follows from the van Dam and Slater hypothesis that the uncoupler and substrate compete for a transport carrier system. The inhibition of substrate oxidation by uncouplers in ETPH does not appear to be of the competitive type, however, although it is reversed by BSA [presumably via nonspecific binding between the protein and the uncoupler $(38,39)$ ] but not by ATP. These findings are of interest in view of the report (28) that ATP may reverse the dicoumarolinduced inhibition of succinate oxidation by intact rabbit-kidney mitochondria, and that inhibition is of the competitive type in ETPH (40). On the other hand, Skulachev et al. (41) have reported that the inhibition of succinate oxidation by high concentrations of DNP in rat liver mitochondria is not of the competitive type. Second, it also follows from the van Dam and Slater hypothesis (11) that abolishment of the permeability barrier to substrate ought to result in a reversal of the inhibited state and in the resumption of succinate or NADH oxidation by ETPH. That such is not the case is indicated by the failure of a number of membrane-solubilizing detergents to release inhibition of substrate oxidation. In addition, 
the oxidation of NADH by particles which had previously been treated with either subtilopeptidase $A$ to disrupt membrane structure by means of hydrolyzing membrane proteins, or phospholipase A to hydrolyze membrane phospholipids (42), was still subject to inhibition by uncoupler. This is in agreement with the inhibition, by dicumarol, of succinate-cytochrome $c$ particles reported by Wilson and Merz (40). It should be noted that concentrations of detergents greater than those reported in Table III, and prolonged treatment of the test particles with subtilopeptidase A or phospholipase A, rendered the enzyme preparations incapable of NADH oxidation, possibly by virtue of electron chain splitting between oxidation-reduction components. The most potent argument against application of the van Dam and Slater hypothesis to submitochondrial systems would appear to be the inability of "solubilized" and "open" forms of submitochondrial systems to resist inhibition of substrate oxidation by uncouplers. Electron micrographs of the "soluble" subunits presented by Tzagoloff, McConnell, and MacLennan (29) indicate that this type of preparation is not vesicular and imply that no permeability barrier ought to exist between substrate and dehydrogenase. Preparation B of Hoppel and Cooper (30) prepared with digitonin also appears partially nonvesicular or "open" when examined with the electron microscope (43).

The results of the studies reported herein would appear to be consistent with the suggestions of Margolis, Lenaz, and Baum (44), Kurup and Sanadi (45), Weinbach and Garbus (46), and Skulachev et al. (47) that uncouplers bind either electron transfer or energy transfer components, possibly in the cnergized state. Gross and San Pietro have recently presented evidence for interaction between uncouplers and high-energy intermediates in chloroplasts (48). At very high concentrations of uncoupler a component of the dehydrogenases of submitochondrial particles would appear to be affected, possibly the nonheme iron protein components of the succinate and NADH dehydrogendses. This binding would also appear to be noncompetitive with respect to substrate at high uncoupler concentrations. The possibility of nonheme iron proteins being the site of inhibition by high uncoupler concentrations is attractive since it would explain the almost complete oxidation of cytochromes during partial inhibition and the noncompetitive nature of the inhibition. This interpretation requires that succinate and $\mathrm{NADH}$ are bound to their respective dehydrogenases at sites other than through the nonheme iron moieties. The finding that dithiothreitol, a reagent which protects - SH groups in proteins (49), affords some protection from the inhibitory effects of uncouplers and also tends to release the inhibited state would appear to be consistent with a protection of the labile sulfide of the nonheme iron protein associated with the succinic and $\mathrm{NADH}$ dehydrogenases of the submitochondrial particles (50). It is also of interest in this context that the effect of uncouplers on ATP synthesis in mitochondria is reversed by 2,3-dimercaptopropanol and 2,3-dimercaptoethanol, suggesting the participation of a dithiol in the coupling process (51).

That the binding of uncoupler to a site in the electron transfer chain occurs on the oxygen side of the nonheme iron moieties of the succinate and NADH dehydrogenases is clear from a comparison of the EPR spectra of control and uncoupler-inhibited submitochondrial particles in which only the $\mathrm{FeNH}_{\mathrm{N}}$ was reduced in the uncoupler-inhibited particle upon the addition of NADH. Thus, uncouplers appear to inhibit the electron transfer process at sites on the substrate side of coenzyme $Q$ and on the oxygen side of $\mathrm{FeNH}_{\mathrm{S}}$ or $\mathrm{FeNH}_{\mathrm{N}}$. With this demonstration, the uncouplers of oxidative phosphorylation, at high concentrations, thus join a group of inhibitors acting at a site between $\mathrm{FeNH}_{\mathrm{N}}$ and coenzyme Q such as rotenone, barbiturates, and piericidin (52), and $N, N^{\prime}$. dicyclohexylcarbodiimide $(25,53)$.

It would appear from the experiments described above that, although some of the observations are consistent with the van Dam and Slater hypothesis of uncoupling of oxidative phosphorylation in intact mitochondria, several key observations are not in accord with such hypothesis when it is extrapolated to the submitochondrial particle. 


\section{ACKNOWLEDGMENT}

We are grateful to Dr. Graham Palmer for his participation in the experiments requiring the use of the electron spin resonance spectrometer.

\section{REFERENCES}

1. Beyer, R. E., and MacDonald, J. E, Fed. Proc. 28, 472 (1969).

2. Slater, E. C., And Lewis, S. E., Biochem. $J$. 58, 337 (1954).

3. Stanbury, S. W., and Mudge, G. H., J. Biol. Chem. 210, 949 (1954).

4. Hemker, H. C., Biochim. Biophys. Acta 63, 46 (1962).

5. Hemker, H. C., Biochim. Biophys. Acta 81. 1, 9 (1964).

6. Wenner, C. E., Fed. Proc. 24, 544 (1965).

7. Wilson, D. F., and Merz, R. D., Arch. Biochem. Biophys. 119, 470 (1967).

8. van DAм, K., Biochim. Biophys. Acta 131, 407 (1967).

9. Harris, E. J., van Dam, K., and Pressman, B. C., Nature 213, 1126 (1967).

10. Harris, E. J., Höfer, M. P., and Prfissman, B. C., Biochemistry 6, 1348 (1967).

11. van Dam, K., and Slater, E. C., Proc. Nat. Acad. Sci. U.S.A. 58, 2015 (1967).

12. Hansen, M., and Smith, A. L., Biochim. Biophys. Acla 81, 214 (1964).

13. Bryer, R. E., in "Methods in Enzymology," (R. W. Estabrook and M. E. Pullman, eds.), Vol. 10, p. 519. Academic Press, New York (1967).

14. Sanadi, D. R., Ann. Rev. Biochem. 34, 21 (1965).

15. Löw, H., ANd VALLIN, I., Biochim. Biophys. Acta 69, 361 (1963).

16. Fritz, I. B., and Beyer, R. E., J. Biol. Chem. 244, 3075(1969).

17. Szarkowska, L., Arch. Biochem. Biophys. 113, 519 (1966).

18. Gornall, A. G., Bardawill, C. J., AND David, M. M., J. Biol. Chem. 177, 751 (1949).

19. Estabrook, R. W., in "Methods in Enzymology," (R. W. Estabrook and M. E. Pullman, eds.), Vol. 10, p. 41. Academic Press, New York (1967).

20. Palmer, G., in "Methods in Enzymology" (R. W. Estabrook and M. E. Pullman, eds.), Vol. 10, p. 594. Academic Press, New York (1967).

21. Hansen, R. E., Kalal, T. T., and Beinert, H., Anal. Biochem. $\mathbf{2} 0,40$ (1967).

22. Allmann, D. W., Bachmann, E., OrmeJohnson, N., Tan, W. C., and Green, D. F., Arch. Biochem. Biophys. 125, 981 (1968).
23. Williamson, R. L., and Metcalf, R. L., Science 158, 1694 (1967).

24. Lardy, H. A., Graven, S. N., and Estrada-O, S., Fed. Proc. 26, 1355 (1967).

25. Beyer, R. H., Brinker, K. R., and Crankshaw, D. L., Can. J. Biochem. 47, 117 (1969).

26. Beyle, R. E., Can. J. Biochem. 46, 677 (1968).

27. Beyer, R. E., Peters, J., And Ikuma, H., Plant Physiol. 43, 1395 (1968).

28. Papa, S., Lofrumento, N. E., Paradies, G., and Quagliariello, E., Biochim. Biophys. Acta 153, 306 (1968).

29. Tzagoloff, A., McConnell, D. G., and Maclannan, D. H., J. Biol. Chem. 243, 4117 (1968).

30. Hoppel, C., and Cooper, C., Biochem. J. 107, 367 (1968).

31. Brinert, H., in "Non Heme Iron Proteins" (A. San Pietro, ed.), p. 23. The Antioch Press, Yellow Springs, Ohio (1965).

32. Rieske, J. S., in "Non-IIeme Iron Proteins" (A. San Pietro, ed.), p. 461. The Antioch Press, Yellow Springs, Ohio (1965).

33. Lardy, H. A., Paetkau, V., and Walter, P., Proc. Nat. Acad. Sci., U.S.A. 53, 1410 (1965).

34. Haslam, J. M., and Krebs, H. A., Biochem.J. 107, 659 (1968).

35. Greenspan, M. D., and Purvis, J. L., $J$. Biol. Chem. 243, 2921 (1968).

36. Quagliarifllo, E., AND Palmieri, F., in "Atti del Seminario di Studi Biologici" (E. Quagliariello, ed.), Vol. 3, p. 5. Adriatica Editrice, Bari (1967).

37. Quagliariello, E., and Palmiert, F., Eur. I. Biochem. 4, 20 (1968)

38. Waterhouse, C., and Witter, R. F., Arch. Biochem, Biophys. 85, 1 (1959).

39. Weinbaci, E. C., and Garbus, J., J. Biol. Chem. 241, 3708 (1966).

40. Wilson, D. F., And Merz, R., Arch. Biochem. Biophys. 129, 79 (1969).

41. Skulachev, V. P., Sharaf, A. A., YaguJZinsky, L. S., Jasaitis, A. A., Liberman, E. A., And Topali, V. P., Curr. Mod. Biol. 2, 98 (1968).

42. Fleischer, S., Casu, A., and Fleischer, B., Fed. Proc. 23, 2305 (1964).

43. Morton, D. J., Hoppel, C., And Cooper, C., Biochem. J. 107, 377 (1968).

44. Margolis, S. A., Lenaz, G., and Baum, H., Arch. Biochem. Biophys. 118, 224 (1967).

45. Kurup, C. K. R., and Sanadi, D. R., Arch. Biochem. Biophys, 126, 722 (1968).

46. Weinbach, E. C., And Garbus, J., Nature 221, 1016 (1969). 
47. Skulachev, V. P., Sharaf, A. A., and Liberman, E. A., Nature 216, 719 (1967).

48. Gross, E., and San Pietro, A., Arch. Biochem. Biophys. 131, 49 (1969).

49. Cleland, W. W., Biochemistry 3, 480 (1964).

50. Tyler, D. D., Gonze, J., Estabrook, R. W., AND Butow, R. A., in "Non-Heme Iron Proteins" (A. San Pietro, ed.), p. 447. The Antioch Press, Yellow Springs, Ohio (1965).
51. Fluharty, A. L., and Sanadi, D. R., Biochemistry 2, 519 (1963).

52. Palmer, G., Horgan, D. J., Tisdale, H., Singer, T. P., and Beinfrt, H., I. Biol. Chem. 243, 844 (1968).

53. Beyer, R. E., Crankshaw, D. L., and Kuner, J. M., Biochem. Biophys. Res. Commun. 28, 758 (1967). 